\title{
Effects of Field Applied Residues and Length of Exposure to Tebufenozide on the Obliquebanded Leafroller (Lepidoptera: Tortricidae)
}

\author{
DANIEL E. WALDSTEIN AND W. H. REISSIG ${ }^{1}$ \\ Department of Entomology, Cornell University, New York State Agricultural Experiment Station, Geneva, NY 14456
}

J. Econ. Entomol. 94(2): 468-475 (2001)

\begin{abstract}
Studies were conducted with the obliquebanded leafroller, Choristoneura rosaceana (Harris), and tebufenozide to determine the influence of various factors on the efficacy of this insecticide under field conditions. Larvae were exposed to apple foliage collected from commercial orchards at different intervals after insecticide applications. Mortality of neonates on actively growing (terminal) and mature (spur) foliage $10 \mathrm{~d}$ after an airblast sprayer application of tebufenozide was 0 and $35-74 \%$, respectively. Feeding by larvae was also assessed on collected foliage. There was significantly less feeding on tebufenozide-treated foliage than chlorpyrifos- and nontreated foliage $(P<0.05)$. In the second study, to determine the efficacy of tebufenozide in the absence of larval movement to terminals with sublethal residues, terminal foliage with obliquebanded leafroller larvae was collected from two commercial orchards $24 \mathrm{~h}$ after an airblast sprayer application of tebufenozide. After larvae were confined on this terminal foliage in the laboratory for $10 \mathrm{~d}$, mortality was $>90 \%$. In the third study, to examine the effects of obliquebanded leafroller movement to foliage with sublethal residues, we designed a laboratory bioassay in which larvae were exposed to foliage treated with tebufenozide and transferred to untreated foliage after various exposure intervals. The higher the concentration of tebufenozide, the less exposure time was necessary to cause high levels of mortality of neonates. The terminal feeding behavior of obliquebanded leafroller larvae, low residues on terminal foliage before the end of the typical 2 -wk spray interval, and the length of exposure necessary for high levels of mortality may decrease the effectiveness of tebufenozide for obliquebanded leafroller control.
\end{abstract}

KEY WORDS Choristoneura rosaceana, apple, tebufenozide, residue, exposure

The obliquebanded LEAFroller, Choristoneura rosaceana (Harris), is an important pest of apples in the United States and Canada. Although obliquebanded leafrollers are polyphagous feeders (Sanderson and Jackson 1909), larvae in apple orchards primarily feed on actively growing terminal foliage (Chapman and Lienk 1971). Resistance to azinphos-methyl, chlorpyrifos, and esfenvalerate has made this orchard pest increasingly difficult to manage (Reissig et al. 1986, Lawson et al. 1997, Waldstein et al. 1999). Although chlorpyrifos and esfenvalerate still effectively control populations of obliquebanded leafrollers in some commercial orchards in New York, many apple growers in New York are using insecticides other than the traditional organophosphates and pyrethroids to control this pest (e.g., Bacillus thuringiensis and spinosad). In addition to the development of insecticide resistance, the toxicity of pyrethroids to beneficials (Hull and Starner 1983) and the potential loss of organophosphates because of the Food Quality Protection Act (1996) provide incentives for apple growers to begin using other insecticides. Unlike their broad spectrum predecessors, most of these new insecticides are rel-

\footnotetext{
${ }^{1}$ To whom reprint requests should be addressed.
}

atively selective to specific groups of insects. These selective insecticides have the advantage of preserving more of the natural enemies of a pest, but may require growers to apply more insecticides in an apple orchard system like New York with pests from several different insect orders. Because most of these new insecticides must be ingested and have little contact activity, they are slower acting than many of the traditional contact insecticides (e.g., organophosphates and pyrethroids). Some of these new insecticides also have shorter residuals than commonly used orchard insecticides. As our knowledge about the use of these new insecticides in the field increases, the control of orchard pests should improve.

Tebufenozide (Confirm, Rohm \& Haas, Philadelphia, PA) is a new insect growth regulator (IGR) that is selective for lepidopteran pests (Dhadialla et al. 1998). Field tests for the control of obliquebanded leafroller have been conducted in commercial orchards in New York with tebufenozide (Reissig et al. 1996, 1997, 1998, 1999). Tebufenozide has typically been comparable to but no better than currently used insecticides. Because IGRs affect the endocrine system, they generally act more slowly on target pests than traditional neurotoxins (Dhadialla et al. 1998). 
This has been demonstrated with tebufenozide on a related leafroller species, the tufted apple budmoth, Platynota idaeusalis (Walker) (Biddinger et al. 1996).

This study was designed to investigate how the biology of obliquebanded leafroller larvae and the toxological properties of tebufenozide can influence the efficacy of this compound under field conditions. The first objective was to compare the toxicity of foliar residues of tebufenozide to obliquebanded leafroller neonates at different intervals throughout a typical spray period. Mortality comparisons were made between immature (terminal) and mature (spur) foliage. Tebufenozide was also compared with two other commonly used orchard insecticides, chlorpyrifos and esfenvalerate, and another IGR and ecdysone agonist, methoxyfenozide.

Because decreased feeding has been observed in other Lepidoptera exposed to tebufenozide and its analog, RH-5849 (Wing et al. 1988, Tateishi et al. 1993, Retnakaran et al. 1997), we also examined foliage consumption by neonates to determine if feeding reduction is an additional sublethal benefit from tebufenozide applications. Numerous field tests have been conducted to determine the efficacy of tebufenozide for obliquebanded leafroller control (Reissig et al. 1996, 1997, 1998, 1999 ). These tests measured the effectiveness of control by determining the percentage of terminals infested with larvae and level of fruit injury. However, the mortality to obliquebanded leafroller larvae from tebufenozide exposure was not assessed in these studies. Subsequent studies have also shown that larvae do not remain in the same terminal feeding shelters for long periods (Waldstein 2000). In the second study, we determined mortality in the absence of terminal growth or movement of larvae to foliage with sublethal residues after tebufenozide was applied in two commercial orchards. Finally, because larvae move from terminal feeding sites frequently (Waldstein 2000) and laboratory studies have shown that tebufenozide is relatively slow to cause mortality (Biddinger et al. 1996), we designed a laboratory bioassay to examine the effects of larvae moving from treated to untreated foliage after different exposure intervals.

\section{Materials and Methods}

Field-Aged Leaf Residue Bioassay. In the summer of 1997, four applications of tebufenozide (Confirm 2 flowable [F], Rohm \& Haas), $0.05 \mathrm{~kg}$ (AI)/ha were made at 10- to 15-d intervals in two commercial apple orchards in western New York. Apple cultivars included 'Empire' (Buhr orchard) and 'Ida Red' (Nesbitt orchard). Treatments were arranged in a randomized complete block design according to Reissig et al. (1998). The size of the treatment blocks ranged from 9 to 39 trees in three rows. Control (untreated) plots were 12-36 trees in three rows. Ida Red trees were $3.0 \mathrm{~m}$ high and planted 3.7 by $6.1 \mathrm{~m}$ apart. Empire trees were $3.0 \mathrm{~m}$ high and planted 2.7 by $6.1 \mathrm{~m}$ apart. Treatments were applied with a truck-mounted airblast sprayer calibrated to deliver 935 liters/ha. The first
Table 1. The number of total samples and samples with control mortality less than or equal to $20 \%$ for each orchard, year, insecticide, colony, and foliage type

\begin{tabular}{lclccc}
\hline \hline Orchard & Year & \multicolumn{1}{c}{ Insecticide } & Colony & Foliage & $\begin{array}{c}\text { Total samples } \\
(\leq 20)^{a}\end{array}$ \\
\hline Nesbitt & 1997 & Tebufenozide & B & S & $8(5)$ \\
Nesbitt & 1997 & Tebufenozide & B & T & $8(2)$ \\
Buhr & 1997 & Tebufenozide & B & S & $8(3)$ \\
Buhr & 1997 & Tebufenozide & B & T & $8(6)$ \\
Buhr & 1997 & Chlorpyrifos & B & T & $8(6)$ \\
Buhr & 1997 & Esfenvalerate & B & T & $4(3)$ \\
Nesbitt & 1998 & Tebufenozide & B & S & $10(7)$ \\
Nesbitt & 1998 & Tebufenozide & L & S & $9(0)$ \\
Zingler & 1998 & Tebufenozide & B & S & $22(17)$ \\
Zingler & 1998 & Tebufenozide & L & S & $13(3)$ \\
Zingler & 1998 & Tebufenozide & B & T & $5(4)$ \\
Zingler & 1998 & Chlorpyrifos & B & T & $4(4)$ \\
Zingler & 1998 & Esfenvalerate & B & T & $4(4)$ \\
Zingler & 1998 & Methoxyfenozide & B & S & $6(6)$ \\
Nesbitt & 1998 & Methoxyfenozide & B & S & $3(1)$ \\
\hline
\end{tabular}

${ }^{a}$ Number of samples with $\leq 20 \%$ mortality in the control.

B, Brown; L, Lyons; S, spur; T, terminal.

spray in both orchards was applied at first trap catch of adult obliquebanded leafrollers (20 June). The other three sprays were applied in the two orchards at 30 June and one July, 15 and 16 July, and 29 and 30 July. A total of 15-30 leaves was collected from the central trees of the middle row in each treatment block because of possible insecticide drift from adjacent blocks. Leaves were collected every 3-5 d throughout each 10- to 15-d spray interval from 23 June to 11 August 1997 (Table 1). All foliage of the same type (i.e., terminal or spur) and insecticide treatment, collected on the same day, was considered one sample (1997 and 1998). Mature (i.e., spur) foliage was sampled after the first two sprays were applied, and terminal foliage from the two most distally located leaves was sampled after the last two sprays were applied. Control leaves were collected from the unsprayed control plot. In 1997, for comparison with tebufenozide, samples were collected from plots sprayed with chlorpyrifos (Lorsban 50\% wettable powder [WP], DowElanco, Indianapolis, IN), $0.27 \mathrm{~kg}(\mathrm{AI}) / \mathrm{ha}$ and esfenvalerate (Asana 0.66 XL emulsifiable concentrate [EC], DuPont, Wilmington, DE), $0.01 \mathrm{~kg}$ (AI) / ha to compare with tebufenozide.

In 1998, the study was repeated in the Nesbitt orchard and conducted in another orchard in western New York with 'Rome' trees (Zingler orchard). Rome trees were $3.0 \mathrm{~m}$ high and planted 2.7 by $6.1 \mathrm{~m}$ apart. A total of 15-30 leaves was collected every 3-5 d throughout each 10- to 15-d spray interval from 19 June to 7 August 1998. Spur foliage was sampled after each of four sprays and terminal foliage was sampled after the last two sprays. Samples were collected from plots sprayed with chlorpyrifos, esfenvalerate, and methoxyfenozide (Intrepid 80 WP, Rohm \& Haas), $0.05 \mathrm{~kg}(\mathrm{AI}) / \mathrm{ha}$. Foliage from the chlorpyrifos and esfenvalerate blocks was sampled only from the Buhr (1997) and Zingler (1998) orchards. All tebufenozide and methoxyfenozide treatments were applied with a spreader-sticker spray adjuvant (Latron B-1956, Rohm \& Haas), $0.18 \mathrm{~kg} / \mathrm{ha}$. 
Foliage from the field was transported to the laboratory and two 14-mm-diameter discs were cut from leaves with a cork borer. These were placed in $30 \mathrm{ml}$ polystyrene cups with an obliquebanded leafroller neonate $(<48 \mathrm{~h})$. In total, $20-60$ cups with leaf discs and larvae were prepared for each collection period for treatment and control leaves. Mortality of neonates was assessed on leaf samples from 1997 and 1998 after $5 \mathrm{~d}$. Mortality was assessed after $10 \mathrm{~d}$ for samples taken in 1997 to examine the effects of delayed mortality. Samples from both years that had $>20 \%$ mortality in the control were excluded from the data (Table 1). Treatment mortality was adjusted for control mortality according to Abbott (1925).

Larvae for the bioassays in 1997 and 1998 came from the Brown colony, which was started by larvae collected in May 1996 and 1997, respectively, from a commercial apple orchard in western New York. At the time of the bioassay, larvae had spent approximately six generations in the laboratory. Larvae collected from the Brown orchard are resistant to azinphos-methyl and chlorpyrifos (Lawson et al. 1997, Waldstein et al. 1999). Larvae from the Lyons colony were used to compare the response to the Brown colony during 1998. The Lyons colony was collected in May 1994 from a wild site in the town of Lyons, NY, and was reared the same as the Brown colony. This site consisted of an uncultivated stand of apples, Malus spp., intermixed with gray dogwoods, Cornus race$m o s a$, and was $>40 \mathrm{~km}$ from any commercial orchards. The Lyons colony is susceptible to orchard insecticides (Lawson et al. 1997). Once collected, larvae were placed individually into eight dram clear plastic jelly cups containing a pinto bean, Phaseolus vulgaris L., diet modified from Shorey and Hale (1965). When pupae had developed they were placed into plastic bags with damp cotton. The resulting adults mated and laid egg masses. Egg masses were placed into vials and hatched larvae were put onto fava bean, Vicia faba L. (Glass and Hervey 1962), plants and used for the continuation of the colony. For the bioassays, larvae put on field collected apple leaf discs were maintained at $23^{\circ} \mathrm{C}, 50 \% \mathrm{RH}$, and a photoperiod of 16:8 (L:D) h.

Feeding Comparison. Apple leaf discs from the field-aged leaf residue bioassay were also visually examined to determine the percentage of leaf disc that was consumed by neonates. Leaf discs were examined from three treatments, tebufenozide, chlorpyrifos, and unsprayed blocks in 1997. Feeding was only assessed on leaf discs with live larvae so mortality before 5 or $10-d$ evaluation did not influence the results. Data were normalized using an arcsine square-root transformation and analyzed by analysis of variance (ANOVA) (Abacus Concepts 1991). An ANOVA was conducted separately for each foliage type (i.e., spur and terminal) and cultivar (i.e., Ida Red and Empire). Means were separated using a Fisher protected least significant difference (LSD) test. Because of the potential for rounding error, means were carried out to the tenths place even though percentage consumption was estimated using whole numbers.
Mortality of Larvae Confined on Field Foliage. This portion of the study was conducted in 1997 in the same commercial orchards as the Field-Aged Leaf Residue Bioassay study (i.e., Nesbitt and Buhr orchards). Terminal foliage with obliquebanded leafroller larvae was collected from 1 to $3 \mathrm{~m}$ in the exterior canopy of tebufenozide-treated and unsprayed apple trees 24-30 h after tebufenozide was applied with an airblast sprayer. Terminals were cut to $15 \mathrm{~cm}$ and placed in a 175-ml polystyrene cup with $125 \mathrm{ml}$ of water. A 500-ml plastic cup with a lid was used to enclose the larvae and foliage. A total of 152 larvae in terminals from the Nesbitt and 55 larvae from the Buhr orchard was collected from the tebufenozide and unsprayed treatments. Larvae were on average fourth instars. Mortality was assessed at 5, 10, and $15 \mathrm{~d}$ after the terminals had been collected. Treatment mortality was adjusted for control mortality according to Abbott (1925).

Exposure Bioassay. Fava bean leaves were treated by dipping in aqueous solutions of formulated tebufenozide (Confirm 70 WP [wettable powder], Rohm \& Haas) for $5 \mathrm{~s}$. After leaves were allowed to air dry, 14-mm leaf discs were cut out of the leaves with a cork borer. One neonate from the Brown colony was placed into each $30-\mathrm{ml}$ polystyrene cup with two fava bean leaf discs. Larvae from the $\mathrm{F}_{3}$ generation were tested at 12.2, 36.8, and $122.5 \mu \mathrm{g}$ (AI) / ml. These concentrations were chosen based on the $\mathrm{LC}_{50}, \mathrm{LC}_{90}$, and $\mathrm{LC}_{99}$ from a probit analysis on the $\mathrm{F}_{2}$ generation. Three replications of $\approx 40-60$ larvae per replicate were tested at each concentration in addition to a control in which leaves were dipped in distilled water (150-200 larvae per concentration for a total of 679 larvae tested). One-fourth of the total for each concentration was divided into four different exposure durations including 1, 2, 4, and $10 \mathrm{~d}$. After exposure to treated discs, larvae were transferred to nontreated fava bean leaf discs for $9,8,6$, and $0 \mathrm{~d}$, respectively, for a total exposure duration to treated and nontreated foliage of $10 \mathrm{~d}$. Percentage mortality was assessed at $10 \mathrm{~d}$. Mean mortality \pm the standard error of the mean was adjusted according to Abbott (1925). Data from one of the replicates for the 10-d exposure were not included because of high control mortality. Larvae were maintained during the $10 \mathrm{~d}$ at $23^{\circ} \mathrm{C}, 50 \% \mathrm{RH}$, and a photoperiod of 16:8 (L:D) h.

\section{Results}

Field-Aged Leaf Residue Bioassay. Mortality of neonates on spur foliage treated with tebufenozide did not decline substantially throughout the 10- to 15 -d spray interval (Fig. 1 and Table 2). However, mortality of neonates declined considerably on terminal foliage treated with tebufenozide (Figs. 2 and 3). Mortality of neonates on terminal foliage was similar with 5-d exposures to tebufenozide, chlorpyrifos, or esfenvalerate. At $10 \mathrm{~d}$ after the spray application with a 5 -d exposure, mortality of neonates on terminal foliage was $0.0-10.5 \%$ for all three insecticides. At $10 \mathrm{~d}$ after the tebufenozide application on spur foliage, mortality 


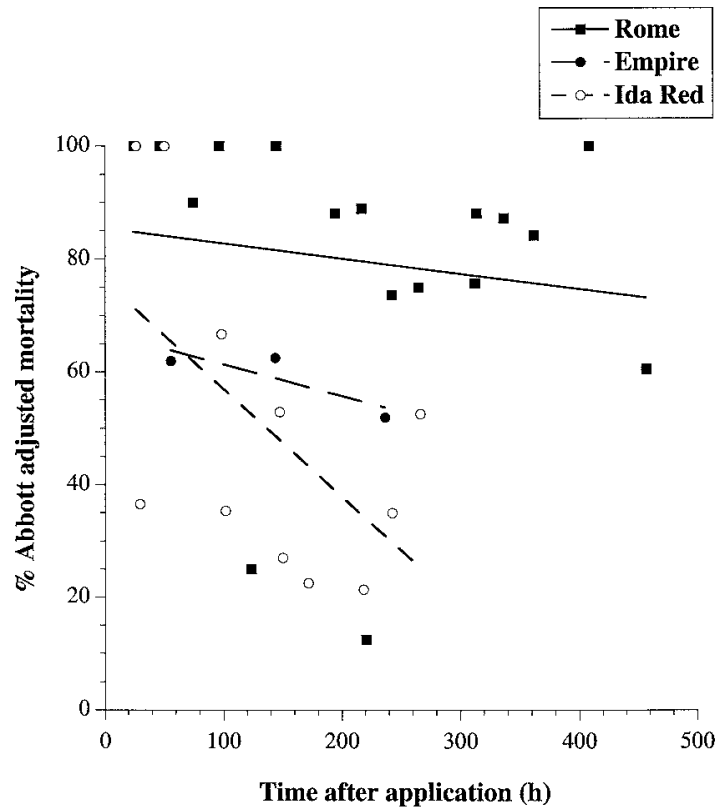

Fig. 1. Mortality of C. rosaceana neonates on Rome, Empire, and Ida Red spur foliage collected at various times from commercial apple orchards after an application of tebufenozide with an airblast sprayer. Larvae were exposed to apple leaves for $5 \mathrm{~d}$.

in the Nesbitt, Buhr, and Zingler orchards was 35, 52, and $74 \%$, respectively. In 1997 , mortality on spur foliage collected $30-243 \mathrm{~h}$ after applications of tebufenozide were made in the Nesbitt orchard was $22.5-36.6 \%$ and $52.5-95.0 \%$ for 5 and 10-d exposures, respectively. A similar increase in mortality from five to $10 \mathrm{~d}$ was observed on samples collected from the Buhr orchard. The mortality at $10 \mathrm{~d}$ was also greater than the 5-d mortality on terminal foliage treated with tebufenozide.

Samples collected from spur foliage treated with methoxyfenozide caused greater neonate mortality than those collected from the tebufenozide-treated trees during the same collection times (Fig. 4). There were also differences in the response to tebufenozide of the Brown (resistant) and Lyons (susceptible) colonies. Mortality in the Brown colony with a 5-d exposure to tebufenozide on spur leaves from the Zin-

Table 2. Linear regression of Abbott's adjusted mortality of $C$. rosaceana neonates and time after insecticide application

\begin{tabular}{llcccc}
\hline \hline Foliage type & Insecticide & $\begin{array}{c}\text { Exposure, } \\
\mathrm{d}\end{array}$ & slope & $\begin{array}{c}\mathrm{y} \\
\text { intercept }\end{array}$ & $R^{2}$ \\
\hline Spur (Nesbitt) & Tebufenozide & 5 & -0.19 & 76.1 & 0.32 \\
Spur (Buhr) & Tebufenozide & 5 & -0.06 & 67.0 & 0.72 \\
Spur (Zingler) & Tebufenozide & 5 & -0.03 & 85.4 & 0.02 \\
Terminal & Tebufenozide & 5 & -0.25 & 91.5 & 0.82 \\
Terminal & Chlorpyrifos & 5 & -0.32 & 108.0 & 0.87 \\
Terminal & Esfenvalerate & 5 & -0.28 & 88.2 & 0.84 \\
Terminal & Tebufenozide & 10 & -0.32 & 120.2 & 0.91 \\
Terminal & Chlorpyrifos & 10 & -0.46 & 121.6 & 0.94 \\
Terminal & Esfenvalerate & 10 & -0.44 & 110.9 & 0.99 \\
\hline
\end{tabular}

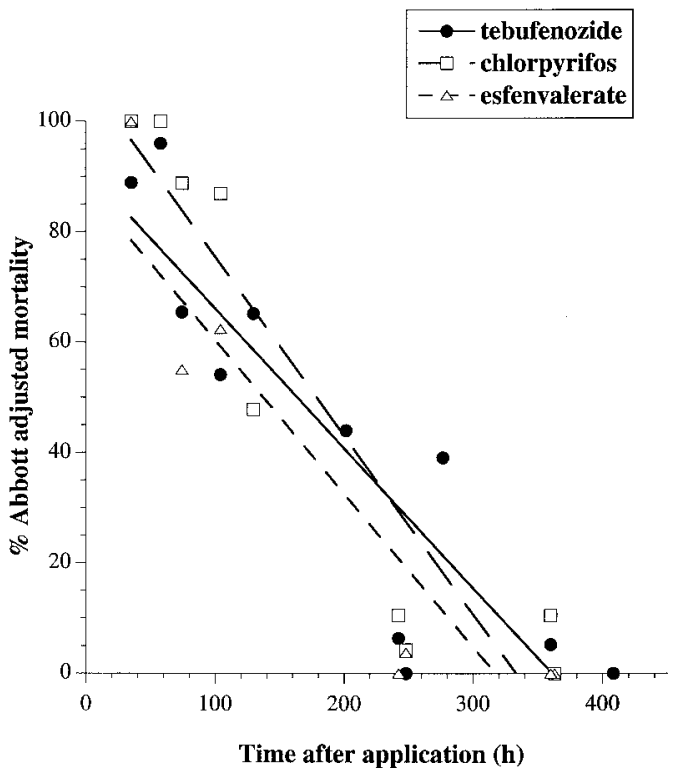

Fig. 2. Mortality of C. rosaceana neonates on Rome and Empire terminal foliage collected at various times from commercial apple orchards after applications of tebufenozide, chlorpyrifos, or esfenvalerate with an airblast sprayer. Larvae were exposed to apple leaves for $5 \mathrm{~d}$.

gler orchard was $73.7-100 \%$ on samples collected $24.5-$ $362 \mathrm{~h}$ after spray applications were made. Mortality in the Lyons colony from the same leaf samples was $100 \%$ for all samples.

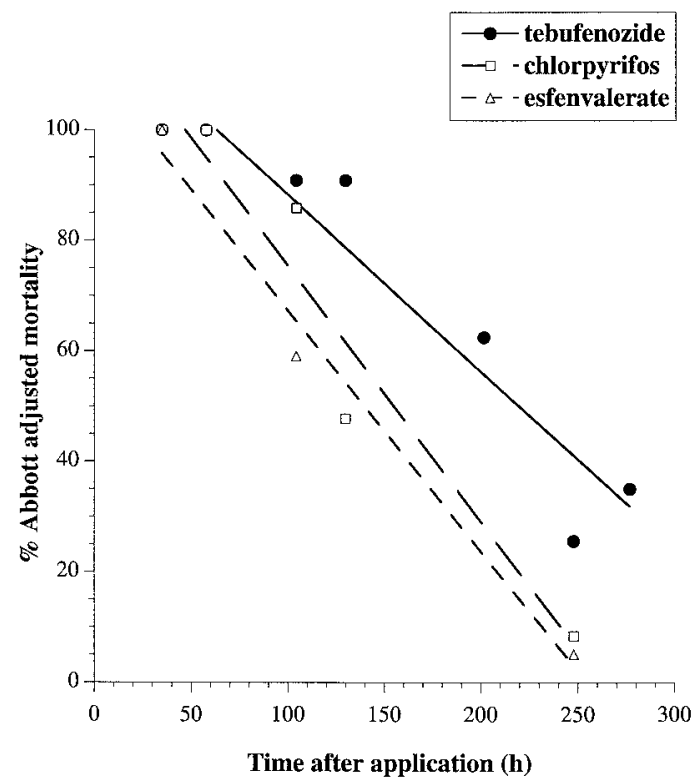

Fig. 3. Mortality of C. rosaceana neonates on Rome and Empire terminal foliage collected at various times from commercial apple orchards after applications of tebufenozide, chlorpyrifos, or esfenvalerate with an airblast sprayer. Larvae were exposed to apple leaves for $10 \mathrm{~d}$. 


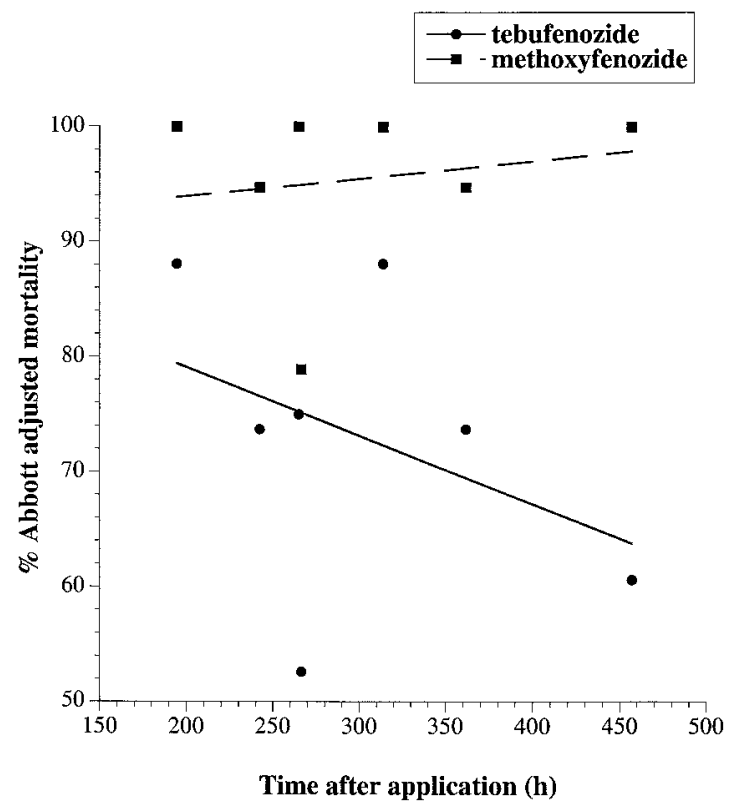

Fig. 4. Mortality of C. rosaceana neonates on Rome spur foliage collected at various times from commercial apple orchards after applications of tebufenozide and methoxyfenozide with an airblast sprayer. Larvae were exposed to apple leaves for $5 \mathrm{~d}$.

Feeding Comparison. The percentage of leaf disc consumed by obliquebanded leafroller neonates after $5 \mathrm{~d}$ was significantly $(P<0.05)$ lower on spur foliage treated with tebufenozide than untreated spur foliage collected from the Buhr (Empire) (1.4 versus 2.4\%) and Nesbitt (Ida Red) (1.9 versus 3.3\%) orchards (Table 3). On terminal foliage, however, feeding after 5 and $10 \mathrm{~d}$ was significantly lower on tebufenozide treated foliage than untreated foliage collected from the Nesbitt orchard only. Neonates consumed a significantly higher percentage of terminal leaf discs treated with chlorpyrifos than tebufenozide from both the Empire (2.6 versus 1.4\%) and Ida Red (3.3 versus $1.6 \%$ ) foliage at 5 -d exposures. Consumption at $10 \mathrm{~d}$ by neonates on Ida Red terminals was significantly different on tebufenozide $(3.0 \pm 1.0)$, chlorpyrifos $(8.7 \pm$ $0.9)$, and untreated $(17.8 \pm 2.5 \%)$ leaf discs. On Empire foliage at $10 \mathrm{~d}$, however, there were no significant differences among the three treatments in the percentage of leaf disc consumed by neonates.

Mortality of Larvae Confined on Field Foliage. Mortality in the tebufenozide treatment at $5 \mathrm{~d}$ for the Nesbitt and Buhr orchards was 63.9 and $72.7 \%$, respectively (Table 4). Control mortality of larvae collected from both orchards was $6.7 \%$. At $10 \mathrm{~d}$, the percentage of mortality in the tebufenozide treatment increased to 93.1 (Nesbitt) and 95.5\% (Buhr). Control mortality at $10 \mathrm{~d}$ was 14.7 and $33.3 \%$, respectively. The percentage of mortality in the tebufenozide treatment at $15 \mathrm{~d}$ was $96.6-100 \%$. Control mortality was $>20 \%$ for larvae from both orchards at $15 \mathrm{~d}$.

Exposure Bioassay. The higher the concentration of tebufenozide, the less exposure time was necessary to
Table 3. Percentage of leaf disc consumed (mean \pm SEM) by C. rosaceana neonates on untreated apple foliage and foliage treated by airblast sprayer with tebufenozide or chlorpyrifos

\begin{tabular}{|c|c|c|c|c|}
\hline Cultivar/foliage type & Treatment & $\begin{array}{c}\text { Exposure } \\
\mathrm{d}\end{array}$ & $\begin{array}{c}\% \\
\text { consumed }^{a}\end{array}$ & $n$ \\
\hline \multirow[t]{2}{*}{ Empire/spur } & Control & 5 & $2.4 \pm 0.2 \mathrm{a}$ & 114 \\
\hline & Tebufenozide & 5 & $1.4 \pm 0.1 b$ & 126 \\
\hline \multirow[t]{4}{*}{ Ida Red/spur } & Control & 5 & $3.3 \pm 0.2 \mathrm{a}$ & 156 \\
\hline & Tebufenozide & 5 & $1.9 \pm 0.1 b$ & 200 \\
\hline & Control & 10 & $6.9 \pm 0.5 \mathrm{c}$ & 124 \\
\hline & Tebufenozide & 10 & $4.7 \pm 0.7 \mathrm{a}$ & 78 \\
\hline \multirow[t]{6}{*}{ Empire/terminal } & Control & 5 & $1.8 \pm 0.1 \mathrm{ab}$ & 281 \\
\hline & Tebufenozide & 5 & $1.4 \pm 0.1 \mathrm{a}$ & 102 \\
\hline & Chlorpyrifos & 5 & $2.6 \pm 0.4 b$ & 52 \\
\hline & Control & 10 & $7.5 \pm 0.7 \mathrm{c}$ & 165 \\
\hline & Tebufenozide & 10 & $6.5 \pm 1.1 \mathrm{c}$ & 50 \\
\hline & Chlorpyrifos & 10 & $10.8 \pm 2.7 \mathrm{c}$ & 18 \\
\hline \multirow[t]{3}{*}{ Ida Red/terminal } & Control & 5 & $2.4 \pm 0.2 \mathrm{a}$ & 200 \\
\hline & Tebufenozide & 5 & $1.6 \pm 0.2 b$ & 84 \\
\hline & Chlorpyrifos & 5 & $3.3 \pm 0.6 \mathrm{a}$ & 44 \\
\hline \multirow[t]{3}{*}{ Ida Red/terminal } & Control & 10 & $8.7 \pm 0.9 \mathrm{c}$ & 96 \\
\hline & Tebufenozide & 10 & $3.0 \pm 1.0 \mathrm{a}$ & 20 \\
\hline & Chlorpyrifos & 10 & $17.8 \pm 2.5 \mathrm{~d}$ & 42 \\
\hline
\end{tabular}

Spur and terminal foliage of Ida Red and Empire cultivars was collected from commercial apple orchards.

ANOVA done separately for each foliage type and cultivar. Means from the same foliage type and cultivar followed by the same letter are not significantly different $(P<0.05 ;$ LSD test $)$. Data normalized using an arcsine square-root transformation prior to analysis. Untransformed data presented.

${ }^{a}$ Mean \% leaf disc consumed by neonate larvae $\pm \mathrm{SE}$ of the mean.

cause high levels of mortality of neonates (Fig. 5). The greatest differences in mortality among exposures occurred at the $12.2 \mu \mathrm{g} / \mathrm{ml}$ concentration. Adjusted mortalities at 10-, 4-, 2-, and 1-d exposures at $12.2 \mu \mathrm{g} / \mathrm{ml}$ were $83.9 \% \pm 0.6,52.8 \% \pm 11.1,22.4 \% \pm 1.8$, and $18.7 \%$ \pm 8.8 , respectively. Although differences in mortality occurred among 1-, 2-, and 4-d exposures at $36.8 \mu \mathrm{g} /$ $\mathrm{ml}$, differences between 4 and 10-d exposures were minimal. Mortality rates were $80-100 \%$ for all exposure durations at the $122.5-\mu \mathrm{g} / \mathrm{ml}$ concentration.

Table 4. Toxicity of tebufenozide to obliquebanded leafroller larvae in apple terminals collected from two commercial orchards $24 \mathrm{~h}$ after an application with an airblast sprayer

\begin{tabular}{llccc}
\hline Orchard & Treatment & $\begin{array}{c}\text { Exposure } \\
(\mathrm{d})\end{array}$ & $\begin{array}{c}\% \\
\text { Mortality }\end{array}$ & $\begin{array}{c}\text { Adjusted } \\
\text { mortality }\end{array}$ \\
\hline Nesbitt & Control & 5 & 6.7 & \\
Nesbitt & Tebufenozide & 5 & 63.9 & 61.3 \\
Buhr & Control & 5 & 6.7 & \\
Buhr & Tebufenozide & 5 & 72.7 & 70.7 \\
Nesbitt & Control & 10 & 14.7 & \\
Nesbitt & Tebufenozide & 10 & 93.1 & 91.9 \\
Buhr & Control & 10 & 33.3 & \\
Buhr & Tebufenozide & 10 & 95.5 & NA \\
Nesbitt & Control & 15 & 22.7 & \\
Nesbitt & Tebufenozide & 15 & 96.6 & NA \\
Buhr & Control & 15 & ND & \\
Buhr & Tebufenozide & 15 & 100 & NA \\
\hline
\end{tabular}

NA, not applicable because control mortality was $>20 \%$. ND, no data collected because mortality at $10 \mathrm{~d}$ was $>20 \%$.

${ }^{a}$ Mortality was adjusted according to Abbott (1925). 


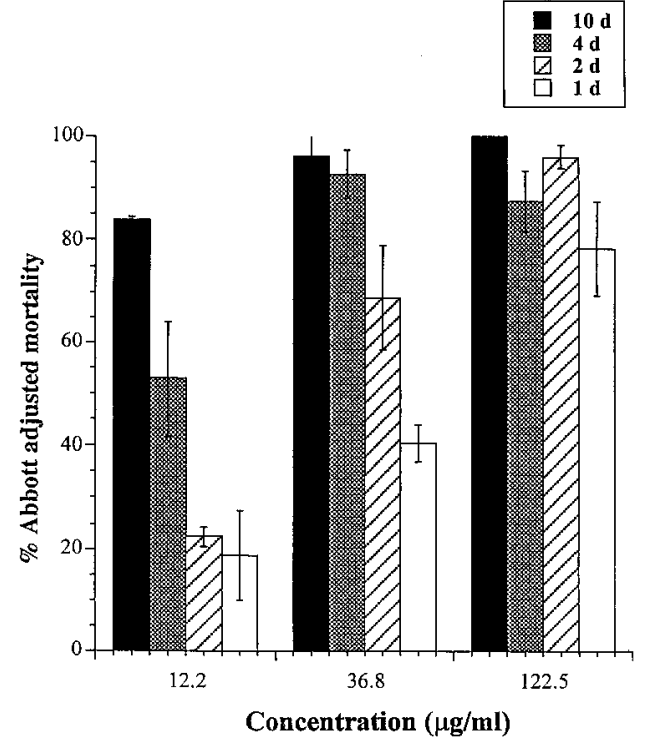

Fig. 5. Effect of three concentrations of tebufenozide on mortality of C. rosaceana neonates after 1-, 2-, 4-, and 10-d exposures.

\section{Discussion}

The effectiveness of tebufenozide residues was influenced by foliage type (i.e., spur and terminal). Mortality rates did not decline greatly throughout the 10- to 15-d spray interval on spur foliage. On terminal foliage, however, mortality rates decreased substantially. This difference was most likely caused by new growth of terminal foliage throughout the 10- to 15-d spray interval. In 1997, because spur and terminal foliage was sampled after different applications, other variables (e.g., precipitation and effect of wind on spray deposition) may have contributed to these differences. However, in 1998, spur and terminal foliage was sampled during the same applications (i.e., last two applications) and results were similar to those in 1997. Although foliage type influenced mortality caused by residues, precipitation did not influence the effectiveness of tebufenozide. Approximately $6 \mathrm{~h}$ after the third spray application in 1997, a rainfall of $47.2 \mathrm{~mm}$ occurred in the Buhr orchard. An additional $32.3 \mathrm{~mm}$ of precipitation occurred 2-5 d later. No precipitation occurred throughout the 2-wk interval after the fourth spray application in 1997. Mortality of larvae on terminal foliage exposed $10 \mathrm{~d}$ to tebufenozide was $100 \%$ for both the third ( $58 \mathrm{~h}$ after spray) and fourth (35 h after spray) applications. Mortality was $90.9 \%$ for both the third and fourth applications, 130 and $105 \mathrm{~h}$, respectively, after tebufenozide was applied. The spray adjuvant Latron B-1956 may have contributed to the lack of any precipitation effect on tebufenozide residues.

Increased mortality of neonates on spur and terminal leaf discs occurred with a longer exposure $(10 \mathrm{~d})$ to tebufenozide. Mortality on terminal foliage treated with chlorpyrifos and esfenvalerate was similar for 5 and 10-d exposures. Biddinger et al. (1996) demonstrated similar results in a laboratory bioassay with tebufenozide and the organophosphate azinphosmethyl on the tufted apple bud moth. Movement of larvae to terminal foliage with sublethal residues may have a greater impact on tebufenozide efficacy than conventional neurotoxins.

None of the three insecticides in the field-aged leaf residue bioassay study effectively controlled neonates on terminals $10 \mathrm{~d}$ after the insecticides were applied with an airblast sprayer. However, $24 \mathrm{~h}$ after tebufenozide was applied, high mortality to larvae occurred when larvae were confined to nongrowing terminals for $10 \mathrm{~d}$. Larvae that emerge from egg masses after an insecticide application and feed on terminal foliage may be exposed to sublethal insecticide residues if applications are made at 2-wk spray intervals. Repeat applications later in the season when a majority of larvae are no longer neonates may be less effective. Biddinger et al. (1998) have demonstrated decreased susceptibility of late instars of the tufted apple bud moth to several orchard insecticides. Obliquebanded leafroller management may be improved by decreasing spray intervals to less than $2 \mathrm{wk}$ and targeting small larvae. Insecticides with shorter residuals than the insecticides used in this study may be less effective against obliquebanded leafrollers. Brunner et al. (1995a) showed that mortality of obliquebanded leafroller neonates to Bacillus thuringiensis (5.7\%) was statistically equivalent to the control $8 \mathrm{~d}$ after 'Delicious' spur leaves were sprayed with a handgun sprayer. Mortality of neonates seven and $14 \mathrm{~d}$ after Delicious spur leaves were treated with tebufenozide using a handgun sprayer was 100 and $93.6 \%$, respectively (Brunner et al. 1995b). Mortality of $\approx 70-100 \%$ occurred in this study with a 5-d exposure 7-14 d after Rome spur foliage from the Zingler orchard was treated with an airblast sprayer. Mortality on Ida Red and Empire spurs collected from the Nesbitt and Buhr orchards was $\approx 20-55 \%, 7-14 \mathrm{~d}$ after tebufenozide was applied. The differences between these two studies may be related to differences between exposures (i.e., 5 versus $7 \mathrm{~d}$ ), application methods (i.e., airblast versus handgun sprayer), cultivars, and susceptibility of Washington and New York populations to tebufenozide.

Tebufenozide significantly decreased but did not prevent foliage feeding by obliquebanded leafroller larvae that were alive at 5 and $10 \mathrm{~d}$. Feeding by larvae was greater on chlorpyrifos- than on tebufenozide-treated foliage. However, because mortality to chlorpyrifos occurred more quickly than tebufenozide, feeding by all larvae (i.e., those dead and alive at 5 and $10 \mathrm{~d}$ ) on foliage treated with chlorpyrifos may have been less than or equal to foliage treated with tebufenozide. Although decreased feeding was also observed with larvae that died from exposures to tebufenozide at 5 and $10 \mathrm{~d}$, larvae did not stop feeding on apple foliage before mortality. It is unknown how this reduction in feeding on foliage treated with tebufenozide relates to fruit damage at harvest, but it may not have a sig- 
nificant impact on fruit damage by obliquebanded leafrollers in New York orchards.

In the absence of terminal growth and obliquebanded leafroller movement, tebufenozide caused high levels of mortality (>90\%) to larvae after a 10-d exposure. Because most of the larvae were in late instars (third to sixth) during the terminal collection, this suggests that tebufenozide is relatively effective against larger larvae. The effectiveness of tebufenozide on late instars of the tufted apple bud moth has been demonstrated (Biddinger et al. 1998). The need for a long exposure to tebufenozide may be the greatest obstacle to successful obliquebanded leafroller control.

The higher the concentration of tebufenozide, the less exposure time was necessary to cause high levels of mortality of neonates. This emphasizes the need to obtain good coverage in the field so larvae are exposed to high concentrations of tebufenozide. The field applied rate of tebufenozide at a volume of 935 liters/ ha (minimum recommended spray volume) equates to a concentration of $340 \mu \mathrm{g} / \mathrm{ml}$ tebufenozide (at the recommended use rate of $0.32 \mathrm{~kg}$ (AI) / ha). Many commercial orchards in New York contain large trees with extensive foliar canopies. Spraying at the minimum recommended spray volume does not provide adequate coverage in these commercial orchards. Because the volume of spray/ha and the time required to make applications are directly proportional, many applicators sacrifice good coverage to increase the efficiency of operations. Doubling the minimum spray volume would increase coverage and still keep the tank concentration more than $\mathrm{LC}_{90}$. Larvae that are exposed to concentrations of tebufenozide more than or equal to $\mathrm{LC}_{90}$ are less likely to survive if they move to foliage with sublethal residues. In this study, at 123 $\mu \mathrm{g} / \mathrm{ml}, 80-100 \%$ mortality occurred at $1-, 2-, 4-$, and 10-d exposures to tebufenozide. The horticultural practice of pruning may also be used to improve insecticide coverage. Summer pruning effectively reduced obliquebanded leafroller damage in large vegetative trees in commercial orchards in New York (Lawson et al. 1998). Obliquebanded leafrollers are generally more difficult to control in larger apple trees (Reissig et al. 1996, 1997, 1998, 1999). This may relate to the increased difficulty to obtain thorough spray coverage in larger trees.

In addition to insecticide residues and length of exposure, other factors such as the sublethal effects of IGRs (Biddinger and Hull 1999), differences among instars in susceptibility to insecticides (Biddinger et al. 1998), and insecticide resistance (Reissig et al. 1986, Biddinger et al. 1996, Lawson et al. 1997, Wearing 1998, Waldstein et al. 1999) can influence the effectiveness of control programs for leafrollers. These factors need to be more thoroughly investigated to improve obliquebanded leafroller management.

\section{Acknowledgments}

We thank Jeffrey Scott and Jan Nyrop for their helpful advice, Cindy Smith for her assistance in rearing the ob- liquebanded leafroller colonies, Richard Cicarelli for his assistance in data collection, Mike and Matt Dunham for their help with spray applications, the Nesbitt, Buhr, and Zingler families for the use of their orchards, and the Rohm \& Haas Company (Philadelphia, PA) for financial support to conduct these studies.

\section{References Cited}

Abacus Concepts. 1991. SuperANOVA. Abacus Concepts, Berkeley, CA.

Abbott, W. S. 1925. A method of computing the effectiveness of an insecticide. J. Econ. Entomol. 18: 265-267.

Biddinger, D. J., and L. A. Hull. 1999. Sublethal effects of selected insecticides on growth and reproduction of a laboratory susceptible strain of tufted apple bud moth (Lepidoptera: Tortricidae). J. Econ. Entomol. 92: 314324.

Biddinger, D. J., L. A. Hull, and B. A. McPheron. 1996. Cross-resistance and synergism in azinphosmethyl resistant and susceptible strains of tufted apple bud moth (Lepidoptera: Tortricidae) to various insect growth regulators and abamectin. J. Econ. Entomol. 89: 274-287.

Biddinger, D. J., L. A. Hull, and E. G. Rajotte. 1998. Stage specificity of various insecticides to tufted apple bud moth larvae (Lepidoptera:Tortricidae). J. Econ. Entomol. 91: 200-208.

Brunner, J. F., M. D. Doerr, and L. O. Smith. 1995a. Bioassay, effect of field-aged residue degradation of Bacillus thuringiensis, 1994. Arthropod Manage. Tests 20: 351.

Brunner, J. F., M. D. Doerr, and L. O. Smith. 1995b. Bioassay, effect of field-aged residue degradation of molt accelerating compounds and Penncap-M, 1994. Arthropod Manage. Tests 20: 346.

Chapman, P. J., and S. E. Lienk. 1971. Tortricid fauna of apple in New York. N.Y. State Agric. Exp. Stn. Geneva Spec. Publ. 87-90.

Dhadialla, T. S., G. R. Carlson, and D. P. Lee. 1998. New insecticides with ecdysteroidal and juvenile hormone activity. Annu. Rev. Entomol. 43: 545-569.

Food Quality Protection Act. 1996. P.L. 104-170. United States Congressional Record. Vol. 142: 110 Stal. 14891538.

Glass, E. H., and G.E.R. Hervey. 1962. Continuous rearing of the red-banded leafroller, Argyrotaenia velutinana. J. Econ. Entomol. 55: 336-340.

Hull, L. A., and V. R. Starner. 1983. Impact of synthetic pyrethroids on major natural enemies and pests of apple in Pennsylvania USA. Ont. Entomol. 76: 122-130.

Lawson, D. S., W. H. Reissig, and C. M. Smith. 1997. Response of larval and adult obliquebanded leafroller (Lepidoptera: Tortricidae) to selected insecticides. J. Econ. Entomol. 90: 1450-1457.

Lawson, D. S., W. H. Reissig, and A. M. Agnello. 1998. Effects of summer pruning and hand fruit thinning on obliquebanded leafroller (Lepidoptera: Tortricidae) fruit damage in New York state apple orchards. J. Agric. Entomol. 15: 113-123.

Reissig, W. H., B. H. Stanley, and H. E. Hebding. 1986. Azinphos-methyl resistance and weight-related response of obliquebanded leafroller (Lepidoptera: Tortricidae) larvae to insecticides. J. Econ. Entomol. 78: 692-699.

Reissig, H., D. H. Dunham, and C. Smith. 1996. Apple, comparison of insecticides against OBLR, 1995. Arthropod Manage. Tests 21: 41-42.

Reissig, H., D. H. Dunham, and C. Smith. 1997. Apple, comparison of insecticides against OBLR, 1996. Arthropod Manage. Tests 22: 25-27. 
Reissig, H., M. Dunham, and C. Smith. 1998. Apple, comparison of insecticides against OBLR, 1997. Arthropod Manage. Tests 23: 28-31.

Reissig, H., M. Dunham, and C. Smith. 1999. Apple, comparison of insecticides against OBLR, 1998. Arthropod Manage. Tests 24: 37-39.

Retnakaran, A., A. MacDonald, W. L. Tomkins, C. N. Davis, A. J. Brownwright, and S. R. Palli. 1997. Ultrastructural effects of a non-steroidal ecdysone agonist, RH-5992, on the sixth instar larva of the spruce budworm, Choristoneura fumiferana. J. Insect Physiol. 43: 55-68.

Sanderson, E. D., and A. D. Jackson. 1909. The obliquebanded leafroller. J. Econ. Entomol. 2: 391-403.

Shorey, H. H., and R. L. Hale. 1965. Mass rearing of the larvae of nine noctuid species on a simple artificial medium. J. Econ. Entomol. 74: 804-809.

Tateishi, K., M. Kiuchi, and S. Takeda. 1993. New cuticle formation and molt inhibition by RH-5849 in the common cutworm, Spodoptera litura (Lepidoptera: Noctuidae). Appl. Entomol. Zool. 28: 177-184.
Waldstein, D. E., W. H. Reissig, J. G. Scott, and R. W. Straub. 1999. Susceptibility of obliquebanded leafroller (Lepidoptera: Tortricidae) populations from commercial apple orchards and an unsprayed habitat in New York to tebufenozide. J. Econ. Entomol. 92: 1251-1255.

Waldstein, D. E. 2000. A study of pest biology and use of tebufenozide to improve management of the obliquebanded leafroller, Choristoneura rosaceana. Ph.D. dissertation, Cornell University, Ithaca, NY.

Wearing, C. H. 1998. Cross-resistance between azinphosmethyl and tebufenozide in the greenheaded leafroller, Planotortrix octo. Pestic. Sci. 54: 203-211.

Wing, K. D., R. A. Slawecki, and G. R. Carlson. 1988. RH5849 a nonsteroidal ecdysone agonist effects on larval lepidoptera. Science 241: 470-472.

Received for publication 20 March 2000; accepted 6 November 2000 . 